\title{
Effect of vitamin D fortified foods on bone markers and muscle strength in women of Pakistani and Danish origin living in Denmark: a randomised controlled trial
}

Ida M. Grønborg ${ }^{1,2^{*}}$ (D) Inge Tetens ${ }^{1,3}$, Elisabeth Wreford Andersen ${ }^{4,5}$, Michael Kristensen ${ }^{6}$, Rikke E. K. Larsen ${ }^{6}$, Thanh L. L. $\operatorname{Tran}^{6}$ and Rikke Andersen ${ }^{1}$

\begin{abstract}
Background: Deficient and insufficient vitamin D status (defined as serum $25(\mathrm{OH}) \mathrm{D}<30 \mathrm{nmol} / \mathrm{L}$ and $>50 \mathrm{nmol} / \mathrm{L}$ ) is prevalent worldwide and associated with decreased muscle strength and poor bone health. We aimed to investigate the effect of vitamin $D$ fortification on bone markers and muscle strength among younger adult women at risk of vitamin $D$ deficiency.

Methods: A 12-week randomised double-blinded placebo-controlled winter intervention trial, providing $30 \mu \mathrm{g}$ vitamin $D_{3} /$ day through fortified yoghurt, cheese, eggs and crisp-bread or similar placebo products. Participants were 143 women of Danish and Pakistani origin 18-50 years of age, living in Denmark, randomised into four groups stratified by ethnicity. Serum 25-hydroxyvitamin D (25(OH)D) by LC-MS/MS and the secondary endpoints: four specific bone markers (osteocalcin (OC), Bone specific Alkaline Phosphatase (BALP), Procollagen type 1 aminoterminal propeptide (P1NP), C-terminal crosslinked telopeptide of type 1 collagen (CTX)) and three muscle strength measures (handgrip, knee extension strength, chair-standing), were assessed using one-way ANOVA, Tukey HSD and subsequent linear ANCOVA models, adjusted for relevant covariates.
\end{abstract}

Results: Significantly increased serum 25(OH)D concentration from 53.3 (17) to 77.8 (14) nmol/L and from 44.5 (21) to 54.7 (18) $\mathrm{nmol} / \mathrm{L}$ among Danish and Pakistani women in the fortified groups, respectively $(P<0.05)$. The bone turnover markers OC, BALP, P1NP and CTX did not change significantly. Muscle strength by handgrip, knee extension and chair-standing test did not change significantly following the intervention.

Conclusions: Consumption of vitamin D fortified foods for 12 weeks did not result in significant changes of the bone turnover markers OC, BALP, P1NP and CTX. Muscle strength measured as hand grip strength, knee extension strength and chair-standing did not change significantly following the intervention.

Keywords: Vitamin D, Ranomised controlled trial, Immigrants, Food, Fortified, Muscle strength, Bone resorption, Bone regeneration

\footnotetext{
* Correspondence: idamag@food.dtu.dk

${ }^{1}$ National Food Institute, Technical University of Denmark, Lyngby, Denmark

${ }^{2}$ Division Diet, Disease Prevention and Toxicology, National Food Institute,

Technical University of Denmark, Lyngby, Denmark

Full list of author information is available at the end of the article
}

(c) The Author(s). 2019 Open Access This article is distributed under the terms of the Creative Commons Attribution 4.0 International License (http://creativecommons.org/licenses/by/4.0/), which permits unrestricted use, distribution, and reproduction in any medium, provided you give appropriate credit to the original author(s) and the source, provide a link to the Creative Commons license, and indicate if changes were made. The Creative Commons Public Domain Dedication waiver (http://creativecommons.org/publicdomain/zero/1.0/) applies to the data made available in this article, unless otherwise stated. 


\section{Introduction}

Vitamin D has a well-established role in the calcium and phosphorus homeostasis and is essential for bone health $[1,2]$. Studies have shown associations between vitamin $\mathrm{D}$ deficiency and insufficiency, here and throughout this paper, defined as serum $25(\mathrm{OH}) \mathrm{D}$ concentrations $<30$ and $<50 \mathrm{nmol} / \mathrm{L}$, respectively [3, 4], and non-skeletal endpoints such as muscular atrophy, muscle pain and decreased muscle strength [5-7]. Vitamin D deficiency and insufficiency is a prevalent worldwide problem [8]. Especially in northerly countries such as Denmark in which the absence of vitamin D from UVB sources during winter increases the risk of deficiency and insufficiency $[9,10]$. Immigrants (first generation and descendants) living in Denmark as well as other Nordic countries are considered at risk of vitamin D deficiency due to factors such as skin colour, cultural clothing and dietary habits [11-13].

Bone tissue is a dynamic structure that undergoes constant remodelling, and optimal bone health is a balance between bone resorption and bone formation. In a case of chronic bone resorption, the bone mineral density (BMD) will decrease with time [14]. The bone turnover can be monitored by bone biomarkers in the blood, and is therefore a potential cost-effective method to complement BMD measurements in situations where BMD is not a feasible endpoint e.g. studies of shorter duration $[14,15]$.

Recent advances have located vitamin D receptors (VDR) within muscle tissue, supporting the assumption that vitamin D has an effect on muscle function $[16,17]$. Some intervention studies have found an effect of vitamin $\mathrm{D}$ on muscle strength $[18,19]$ and some effect in the number of falls [20], while other studies were unable to see an effect [21]. These inconsistent trends may be related to the baseline serum $25(\mathrm{OH}) \mathrm{D}$ concentration and the effect of vitamin $\mathrm{D}$ supplementation is more pronounced on vitamin $\mathrm{D}$ deficient people $(25(\mathrm{OH}) \mathrm{D}$ concentrations $<25-30 \mathrm{nmol} / \mathrm{L})[18,19]$. Additionally, assessment of the effect of vitamin D on muscle strength has primarily been studied among elderly subjects (mainly community dwelling), and there is a lack of data on the effects of vitamin D on muscle strength in young adults deficient in vitamin $\mathrm{D}$ [22]. The mechanism of vitamin $\mathrm{D}$ and muscle function has not been agreed upon, however, it has been hypothesised that the active metabolite of vitamin $\mathrm{D}\left(1,25(\mathrm{OH})_{2} \mathrm{D}\right)$ vitamin $\mathrm{D}$ is involved in the regulation of the calcium flow within the muscle through genomic and non-genomic pathways and is thus important for the contraction of muscle fibres $[5,17]$.

We aimed to investigate the effect of 12 weeks of intervention with vitamin $\mathrm{D}$ fortified foods on markers of bone turnover and muscle strength in a population of women of Danish and Pakistani origin between 18 and 50 years of age, at risk of vitamin D deficiency. Our hypothesis was that 12 weeks of intervention with $30 \mu \mathrm{g}$ vitamin $\mathrm{D}_{3}$ /day would significantly improve muscle strength in a population of Danish and Pakistani women at risk of vitamin D deficiency.

\section{Methods}

\section{Study design}

This paper is based on intervention data from a foodbased randomised controlled trial (RCT) ODIN-FOOD. The intervention was designed to assess the change in serum 25-hydroxyvitamin $D_{3}$ as the primary endpoint following fortification, while measurements of muscle strength and bone turnover markers were secondary outcomes. The main study outcomes of the ODIN $F O O D$ project have been included in a previous publication [23], we will refer to this publication throughout the methods for further details.

The present study was a three month double-blinded RCT. A total of 143 women of Danish $(n=71)$ and Pakistani $(n=72)$ origin between 18 and 50 years at risk of vitamin D deficiency were enrolled in the study (see Table 1). Details of the study design, recruitment (flow diagram), randomisation and blinding has been described previously [23]. The subjects were given four different vitamin $\mathrm{D}$ fortified foods contributing with $30 \mu \mathrm{g} /$ day (intervention group) or non-fortified foods (placebo group). The intervention was performed during the winter months (Jan. - Apr.) to minimise interference from cutaneous produced vitamin D. Participants were seen before the intervention start (January 2016) and at the end of intervention after 3 months (April 2016). At the visits blood was drawn, anthropometrics, dietary vitamin $\mathrm{D}$ intake and muscle strength were measured. The assessed endpoints were hand grip strength, knee extension strength, number of chair-stands in a 30-s chair stand test, and concentrations of four different bone turnover markers (OC, BALP, P1NP, CTX).

Sample size was based on $90 \%$ power (alpha $=5 \%$ ) to detect a change in $25(\mathrm{OH}) \mathrm{D}$ concentration of $20 \mathrm{nmol} / \mathrm{L}$ in the treatment group with a standard deviation (SD) of 23 , and a drop-out rate of $20 \%$.

\section{Participants}

The participants were of Danish and Pakistani origin, recruited from the Copenhagen area, city and suburbs (Denmark, $55^{\circ} \mathrm{N}$ ). The recruitment was carried out in the autumn of 2016 by e-mail, advertisements and networking, as described elsewhere [23]. Inclusion criteria were a low consumption of fish and fish products (less than weekly), a low intake of vitamin D-containing supplements (less than weekly), no use of tanning facilities, no planned sun-holiday (more southerly than $47^{\circ} \mathrm{N}$ ) 
Table 1 Baseline characteristics of participants by study group and ethnicity

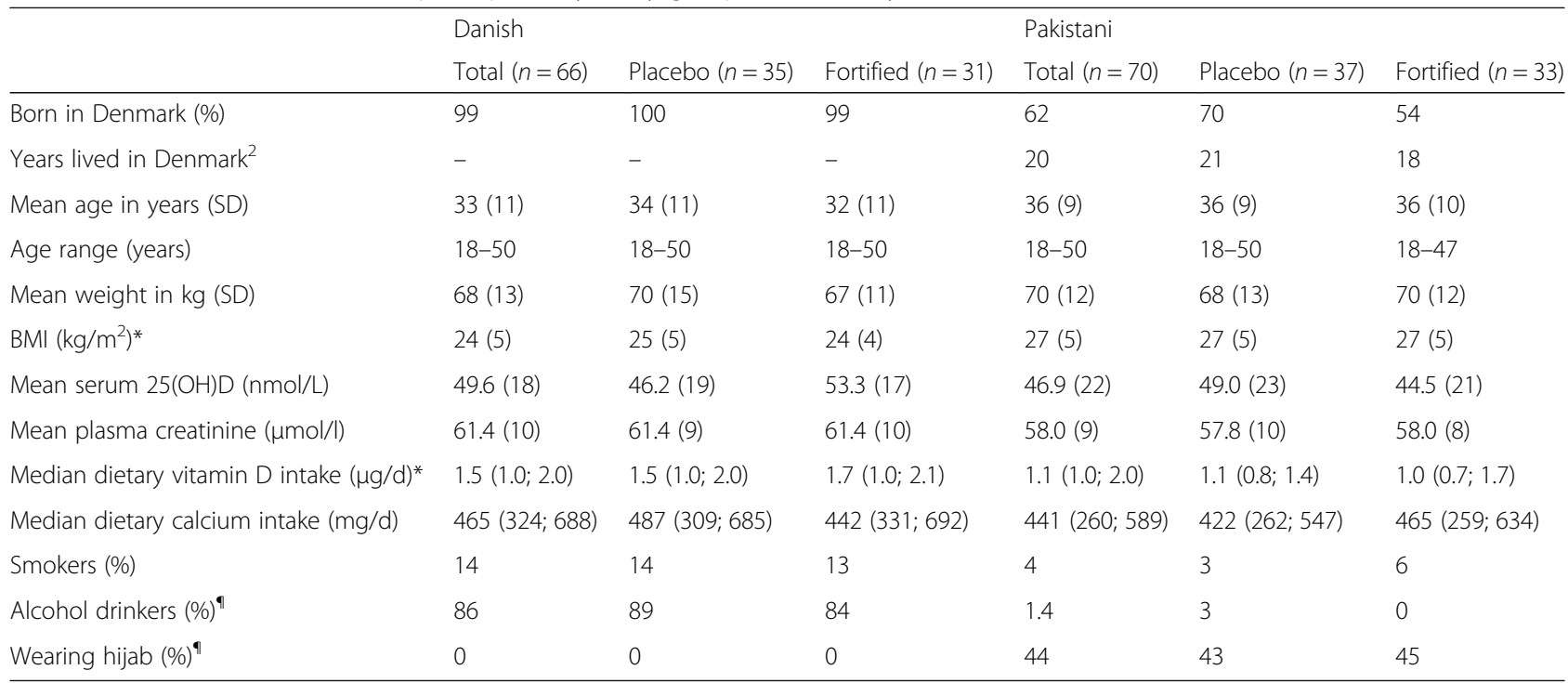

${ }^{1}$ Means and SD unless otherwise specified. If non-normally distributed, medians and $25^{\text {th }}$ and $75^{\text {th }}$ percentiles.

${ }^{2}$ Years lived in Denmark on average, if not born in Denmark.

"Significant difference between Danish (all) and Pakistani (all) women in an unpaired t test $(P<0.05)$.

"Significant difference between Danish (all) and Pakistani (all) women in a Pearson's chi ${ }^{2}$ test.

between October 2015 and May 2016. No upper limit of the concentration of vitamin $\mathrm{D}$ in the supplement was specified as long as the participants stopped taking them at the time of enrolment in the study. Exclusion criteria were pregnancy and breastfeeding, menopause, nonDanish speakers, serious diseases (cancer, server liver or kidney insufficiencies, sarcoidosis and other granulomatous diseases) and medicines affecting the vitamin D metabolism (steroids, antiepileptic, thyroid hormones, bisphosphonates, oestrogen).

\section{Study foods}

The intervention foods were low-fat Milner cheese (gouda) and yoghurt (plain) produced and provided free of cost by FrieslandCampina in the Netherlands, eggs (Livskraft) produced and provided free of cost by Hedegaard in Denmark, and whole wheat biscuits produced by Smørum konditori (confectionary) with ingredients supplied free of cost by Lantmännen Cerealia, Denmark, with vitamin $\mathrm{D}_{3}$ supplied by DSM nutritional products, Switzerland. The study foods were either placebo or fortified with vitamin $\mathrm{D}_{3}$ with the aim of increasing the total vitamin D status in an effective and safe manner in both ethnic groups. Foods highly representative and acceptable in both traditional Danish and Pakistani kitchen were chosen. The daily portion sizes were $150 \mathrm{~g}$ yoghurt, $60 \mathrm{~g}$ cheese, 1 egg and 1 small crisp bread $(9 \mathrm{~g})$. The fortified and non-fortified foods have the same fat percentage and comparable content of nutrients, except for the content of vitamin $\mathrm{D}_{3}$.
Random samples from every batch were analysed for vitamin D content at the National Food Institute in Denmark and the total daily vitamin D content was $29 \mu \mathrm{g} /$ day (further details on vitamin D content, metabolites and methods described elsewhere, [23]).

\section{Measurements}

\section{Blood procurement procedures}

At each of the two study visits non-fasting blood samples were obtained between 9 am and 16 PM for the majority of the samples. Efforts were made to book the endpoint measurement at the same time as baseline visit for each participant.

\section{Anthropometric measures and questionnaires}

Anthropometric measures were height $(\mathrm{cm})$ (wall mounted stadiometer, seca, Hamburg, Germany), weight $(\mathrm{kg})$, waist-hip circumference $(\mathrm{cm})$ (standard tape measure) and body composition (Tanita BC 418 MA, Tokyo, Japan), as described elsewhere [23]. At baseline the participants completed two questionnaires, a general background questionnaire containing questions regarding general health, physical activity (during work and leisure time, if the participants had a job) and lifestyle, and a semi-quantitative Food Frequency Questionnaire (FFQ) estimating the average daily intake of vitamin $\mathrm{D}$ and calcium. The FFQ was a retrospective questionnaire asking about the participants' habitual dietary intake of vitamin D-rich foods over the 3 preceding months. The questionnaire contained the 8 food groups (fish, meat, milk and milk products, egg, cheese, bread, fats and pulses) 
contributing to the majority of dietary vitamin D (98\%) and calcium (71\%) found in a general diet [24]. The weekly compliance was monitored by a self-reported user-friendly compliance questionnaire as described in details elsewhere [23].

\section{Markers of bone turnover}

In this paper we used the bone markers OC, BALP and P1NP for the assessment of the bone formation and CTX as a marker of bone resorption, based on previous studies carried out in a similar population group $[25,26]$.

The biochemical analyses of the bone turnover markers OC, BALP, P1NP, and CTX were performed at the University Hospital Aarhus. OC had a precision of \pm $0.55 \mu \mathrm{g} / \mathrm{L}$ (SD) at a concentration of $19 \mu \mathrm{g} / \mathrm{L}$ and \pm $2.75 \mu \mathrm{g} / \mathrm{L}(\mathrm{SD})$ at a concentration of $92 \mu \mathrm{g} / \mathrm{L}$. BALP had a precision of $\pm 0.45 \mu \mathrm{g} / \mathrm{L}$ (SD) at a concentration of $4.5 \mu \mathrm{g} / \mathrm{L}$ and $\pm 4.6 \mu \mathrm{g} / \mathrm{L}$ (SD) at a concentration of $45.9 \mu \mathrm{g} / \mathrm{L}$. P1NP had a precision of $\pm 1.1 \mu \mathrm{g} / \mathrm{L}$ (SD) at a concentration of $30 \mu \mathrm{g} / \mathrm{L}$ and $\pm 7.6 \mu \mathrm{g} / \mathrm{L}$ (SD) at a concentration of $205 \mu \mathrm{g} / \mathrm{L}$. CTX had a precision of \pm $0.015 \mu \mathrm{g} / \mathrm{L}(\mathrm{SD})$ at a concentration of $0.26 \mu \mathrm{g} / \mathrm{L}$ and \pm $0.03 \mu \mathrm{g} / \mathrm{L}(\mathrm{SD})$ at a concentration of $0.59 \mu \mathrm{g} / \mathrm{L}$.

\section{Muscle function}

Both upper and lower limb muscle function were measured using different physical tests. Upper limb muscle strength was measured as isometric hand grip strength (measured in $\mathrm{kg}$ ) using a digital hand dynamometer (SAEHAN Corporation, South Korea) which have previously been demonstrated to have high inter-rate and test-retest reliability [27]. Participants were seated on a chair with the arm in a $90^{\circ}$ elbow flexion, and the forearm in mid-prone neutral position. The handle of the dynamometer was placed in position 2 , thereby fitting the standard hand size for adults. All participants had two familiarisation trials prior to the maximal contraction test. A minimum of three maximal isometric contractions were conducted with the dominant hand with a 90-s break between each measurement. If the last contraction was the highest, the participants had up to two additional contractions. The instructor gently supported below the instrument to minimised an effect of gravity. Muscle strength was calculated as the mean of the three highest values obtained (averaged peak grip strength). The intra-assay coefficient of variation (CV) for hand grip strength was $4.0 \%$.

Lower limb muscle strength was measured as isometric knee extension strength (measured in $\mathrm{kg}$ ) using a digital handheld muscle tester (MicroFET2, Hoggan Scientific, USA). The MicroFET2 dynamometer was belt-stabilised to the table, so that the instructor would only have to concentrate on holding the dynamometer in the correct position on the ankle [28].The participants were seated on a table fitted with a non-skid material in an upright position with a $90^{\circ}$ hip flexion and arms placed on the lap. The lower leg was hanging down about $1 \mathrm{~cm}$ from the edge of the table without touching the floor. The MicroFET2 dynamometer was placed on the front of the ankle, on the dominant leg, approximately $4 \mathrm{~cm}$ above the lateral malleoli. The participants were asked to stretch their leg as much as they could for approximately $5 \mathrm{~s}$. The participants had two familiarisation trials where they were asked to stretch their leg using $\approx$ half of maximal power. This was followed by 3-5 maximal contractions lasting approximately $5 \mathrm{~s}$ with a 90 -s break between each measurement. Muscle strength was calculated as the mean of the three highest values obtained. The intra-assay $\mathrm{CV}$ for knee extension strength was $4.2 \%$.

Lower limb muscle function was also measured by a 30-s chair-stand test, as a measurement of anaerobic muscle function. Participants were seated on a chair (43 $\mathrm{cm}$ high, without arm rest). Arms were folded across the chest, and the number of full stands achieved in $30 \mathrm{~s}$ were recorded [29].

\section{5(OH)D-measurements and other biochemical measurements}

Serum concentrations of total $25(\mathrm{OH}) \mathrm{D}$ (i.e., $25(\mathrm{OH}) \mathrm{D}_{2}$ plus $25(\mathrm{OH}) \mathrm{D}_{3}$ ) of all serum samples (baseline and endpoint visits) were measured at the Cork Centre for Vitamin D and Nutrition Research, University College Cork (UCC), using the ODIN core LC-MS/MS analytical platform for serum $25(\mathrm{OH}) \mathrm{D}$, described in detail elsewhere [30]. The intra-assay CV of the method was $<5 \%$ for all 25(OH)D metabolites, whilst the inter-assay $\mathrm{CV}$ was $<6 \%$. The LC-MS/MS method at UCC is certified by the Centre for Disease Control and Prevention's Vitamin D Standardization Certification Program (VDSP).

Serum creatinine a marker of muscle mass [31] was measured at the University Hospital Aarhus. Creatinine had the following precisions at specific concentrations: At $81 \mu \mathrm{mol} / \mathrm{L} \pm 7.4 \%(95 \% \mathrm{CI})$ and at $567.0 \mu \mathrm{mol} / \mathrm{L} \pm$ $5.0 \%(95 \% \mathrm{CI})$ and biological variation of $\pm 11.9 \%$ (95\% CI).

\section{Statistical analysis}

Results are shown as means (SD) unless otherwise specified. Descriptive statistics were calculated using a twosample $t$ test or the non-parametric Kruskal Wallis test for comparing the two ethnic groups. Categorical variables were compared using a Pearson's chi-square test. Simple one-way ANOVA were used to test for significant baseline comparison across the four study groups (DK placebo, DK fortified, PA placebo, Pa fortified) and 
a subsequent Tukey HSD test showed which groups were responsible for the difference.

ANCOVA analysis of covariance was used to analyse the effect of the intervention on the respective outcome variables (muscle strength and markers of bone turnover). We adjusted for age, ethnicity, BMI and study group as well as the respective baseline variables. Finally, to check the model assumptions the standardized residuals of the models were assessed visually for normality, variance homogeneity and linearity. Compliance was estimated individually by dividing the individual amount of food with the individual self-reported compliance the final compliance is shown as the percentage consumed foods of delivered foods.

Statistical analyses were performed using RStudio for Windows [32] (Version 1.1.414 - ๔ 2009-2018 Rstudio, Inc.) with a significance level of $\alpha=0.05$.

\section{Results}

\section{Subject characteristics}

Baseline characteristics relating to anthropometrics, dietary intake of vitamin D and calcium, vitamin D status are listed in Table 1, a flow diagram has previously been published [23]. The mean baseline vitamin D status among the women of Danish and Pakistani origin were 49.6 (18) and 46.9 (22) nmol/L, respectively (no ethnic difference $P=0.8$ ). At baseline 9 and $24 \%$ of the participants of Danish and Pakistani origin, respectively, had a vitamin $\mathrm{D}$ status below $30 \mathrm{nmol} / \mathrm{L}$ (distribution data shown elsewhere [23]). The women of Pakistani origin had a slightly higher BMI and fat percentage compared to the women of Danish origin (t test, both $P<0.001$, data not shown) and lower lean mass (t test, $P<0.001$, data not shown).

Baseline self-reported physical activity and health are listed in Table 2. Among the participants of Danish origin $24 \%$ reported their health as "very good", this was only the case with $7 \%$ among the participants of Pakistani origin. Accordingly, 33\% the women of Pakistani origin reported "somewhat bad", whereas only $4 \%$ of the women of Danish origin reported this. When asked to compare the overall health with others of the same age, 6 and 26\% of the women of Danish and Pakistani origin, respectively, reported "worse".

\section{Intervention effects on bone markers and muscle strength}

Generally, the differences seen at baseline were also observed at endpoint. We saw no significant change in bone turnover markers following the intervention, unadjusted ANOVA $(P>0.05$, Table 3$)$. We saw no significant differences in the changes in muscle strength (Table 4), despite that the intervention was effective in increasing the mean serum $25(\mathrm{OH}) \mathrm{D}$ concentration
Table 2 Baseline self-reported physical activity and self-rated health

\begin{tabular}{|c|c|c|}
\hline & Danish & Pakistani \\
\hline \multicolumn{3}{|l|}{ Total physical activity } \\
\hline Physical activity score, no job', n (\%) & $\mathrm{n}$ total $\mathrm{DK}=3$ & $\mathrm{n}$ total $\mathrm{Pa}=22$ \\
\hline 1: Sedentary & $0(0 \%)$ & $3(14 \%)$ \\
\hline 2: Light & $1(33 \%)$ & $15(68 \%)$ \\
\hline 3: Medium & $2(67 \%)$ & $3(14 \%)$ \\
\hline 4: Heavy & $0(0 \%)$ & $1(4 \%)$ \\
\hline $\begin{array}{l}\text { Physical activity score, job and } \\
\text { leisure, } \mathrm{n}(\%)\end{array}$ & $\mathrm{n}$ total $\mathrm{DK}=63$ & $\mathrm{n}$ total $\mathrm{Pa}=48$ \\
\hline 1: Sedentary & $5(8 \%)$ & $10(21 \%)$ \\
\hline 2: Light & $31(49 \%)$ & $28(58 \%)$ \\
\hline 3: Medium & $22(35 \%)$ & $9(19 \%)$ \\
\hline 4: Heavy & $5(8 \%)$ & $1(2 \%)$ \\
\hline Self-rated health, n (\%) & $\mathrm{n}$ total $\mathrm{DK}=66$ & $\mathrm{n}$ total $\mathrm{Pa}=70$ \\
\hline 1: Very good & $24(36 \%)$ & $5(7 \%)$ \\
\hline 2: Somewhat good & $37(56 \%)$ & $34(49 \%)$ \\
\hline 3: Somewhat bad & $4(6 \%)$ & $23(33 \%)$ \\
\hline 4: Very bad & $1(2 \%)$ & $8(11 \%)$ \\
\hline $\begin{array}{l}\text { Self-rated health compared to } \\
\text { others of same age, } \mathrm{n}(\%)\end{array}$ & $\mathrm{n}$ total $\mathrm{DK}=66$ & $\mathrm{n}$ total $\mathrm{Pa}=70$ \\
\hline 1: A lot better & $6(9 \%)$ & $4(6 \%)$ \\
\hline 2: Somewhat better & $16(24 \%)$ & $21(30 \%)$ \\
\hline 3: The same & $40(61 \%)$ & $27(38 \%)$ \\
\hline 4: Worse & $4(6 \%)$ & $18(26 \%)$ \\
\hline
\end{tabular}

${ }^{1}$ Participant divided according to job situation in order to determine physical activity during their daily activities. Participant with a job were asked about activity during work and leisure time, participants without a job were asked about activities throughout the day, the only difference were the formulation of the questions. Physical activity score is a mean of eight self-rated questions on physical activity and sedentary time. The questions on physical activity is adapted from a previous intervention study [33]

from 53.3 (17) to 77.8 (14) nmol/L and from 44.5 (21) to 54.7 (18) nmol/L among the fortified Danish and Pakistani women, respectively $(P<0.05)$ (data shown in full in previous publication [23]).

\section{Linear models}

The intervention with vitamin D fortified foods showed no effect on the markers of bone turnover OC, CTX, BALP and P1NP, analysed in an ANCOVA including the baseline covariates age, ethnicity, intervention group and BMI. Only the baseline concentration of each marker of bone turnover had a significant influence on the endpoint concentration of the specific bone marker (Table 5).

Considering the muscle strength tests, fortification with vitamin D did not have a significant effect on the muscle strength measured as hand grip strength, only the baseline hand grip strength had a significant influence on the endpoint hand grip strength (Table 6). 
Table 3 Markers of bone turnover: OC, CTX, BALP, P1NP at baseline, endpoint and the change following intervention ${ }^{1}$

\begin{tabular}{|c|c|c|c|c|c|}
\hline & \multicolumn{2}{|l|}{ Danish } & \multicolumn{2}{|l|}{ Pakistani } & \multirow[b]{2}{*}{$p^{2}$} \\
\hline & Placebo $(n=35)$ & Fortified $(n=31)$ & Placebo $(n=37)$ & Fortified $(n=33)$ & \\
\hline \multicolumn{6}{|l|}{$\mathrm{OC}(\mu \mathrm{g} / \mathrm{L})$} \\
\hline Baseline & $23.9(9.6)^{d}$ & $25.2(8.7)^{\mathrm{bc}}$ & $19.6(8.4)^{c}$ & $18.2(5.6)^{\mathrm{bd}}$ & 0.001 \\
\hline Endpoint & $22.3(9.0)$ & $22.7(6.8)^{b}$ & $19.5(8.9)$ & $17.4(5.0)^{b}$ & 0.03 \\
\hline Change & $-1.2(4.2)$ & $-2.3(4.6)$ & $-0.20(4.0)$ & $-0.5(2.9)$ & 0.19 \\
\hline \multicolumn{6}{|l|}{ CTX (ng/mL) } \\
\hline Baseline & $0.25(0.14)$ & $0.30(0.15)$ & $0.27(0.19)$ & $0.21(0.1)$ & 0.13 \\
\hline Endpoint & $0.23(0.14)$ & $0.26(0.12)$ & $0.24(0.16)$ & $0.19(0.1)$ & 0.20 \\
\hline Change & $-0.006(0.1)$ & $-0.05(0.1)$ & $-0.03(0.1)$ & $-0.02(0.1)$ & 0.38 \\
\hline \multicolumn{6}{|l|}{ BALP $(\mu \mathrm{g} / \mathrm{L})$} \\
\hline Baseline & $15.5(7.0)$ & $16.6(5.2)$ & $15.9(5.2)$ & $16.9(7.9)$ & 0.79 \\
\hline Endpoint & $13.4(5.4)$ & $14.0(4.4)$ & $14.6(4.9)$ & $14.6(6.0)$ & 0.74 \\
\hline Change & $-1.5(3.5)$ & $-1.5(3.6)$ & $-1.4(2.1)$ & $-1.8(4.5)$ & 0.97 \\
\hline \multicolumn{6}{|l|}{ P1NP ( $\mu \mathrm{g} / \mathrm{L})$} \\
\hline Baseline & $50.7(25.2)$ & 54.6 (19.6) & 46.6 (19.6) & $48.1(17.2)$ & 0.42 \\
\hline Endpoint & $46.4(23.8)$ & $51.1(16.8)$ & $48.5(21.0)$ & $45.7(14.7)$ & 0.72 \\
\hline Change & $-2.0(7.9)$ & $-2.6(11.0)$ & $1.7(10.3)$ & $-1.7(10.4)$ & 0.31 \\
\hline
\end{tabular}

${ }^{1}$ Means and SD unless otherwise specified.

${ }^{2} P$ values for comparisons over the four study groups were determined with the use of a one-way ANOVA followed by Tukey's HSD test. Significant comparisons a: DK Placebo vs DK Fortified, b: PA Fortified vs DK Fortified, c: PA Placebo vs DK Fortified, d: PA Fortified vs DK Placebo, e: PA Placebo vs DK Placebo, f: PA Placebo vs PA Fortified.

OC Osteocalcin, BALP Bone specific Alkaline Phosphatase, P1NP Procollagen type 1 amino-terminal propeptide, CTX C-terminal crosslinked telopeptide of type 1 collagen

\section{Discussion}

Following the 12-week intervention with vitamin D fortification no significant changes in the concentration of the markers of bone turnover OC, BALP, P1NP and CTX. Additionally, no significant increase in muscle strength in the two fortified groups and no significant decrease in muscle strength of the placebo groups were measured.

We expected a low baseline vitamin D status among our study population $(<30 \mathrm{nmol} / \mathrm{L})$ as a previous Danish study from 2008, also including women of Pakistani origin found a very low baseline vitamin $D$ status $(<15$ $\mathrm{nmol} / \mathrm{L}$ ) [11, 25], and because a recent Danish study found a large proportion of participants $(n=2565)$ with a serum $25(\mathrm{OH}) \mathrm{D}$ status below $50 \mathrm{nmol} / \mathrm{L}$ in at least one of the seasons [34], suggesting that insufficiency is prevalent. In order to recruit only women at risk of vitamin D deficiency in the present study, we used restrictive inclusion criteria allowing only women with a low intake of fish and supplements as well as a low UVB exposure to be enrolled in the study (described elsewhere in detail, [23]). Despite vitamin D exposure-specific inclusion criteria, the mean baseline vitamin $\mathrm{D}$ status of the participants in this trial were 49.6 (18) and 46.9 (22) $\mathrm{nmol} / \mathrm{L}$ in participants of Danish and Pakistani origin, respectively. We saw that $9 \%$ of the participants of Danish origin and $24 \%$ of participants of Pakistani origin had a serum 25(OH)D concentration below $30 \mathrm{nmol} / \mathrm{L}$ at baseline (data shown in full length elsewhere [23]). In the previously mentioned study from 2008 by Andersen et al. the distribution of extremely deficient and deficient vitamin D status among the women of Pakistani origin were reported as serum $25(\mathrm{OH}) \mathrm{D}$ concentration $\leq 10$ or $>10-\leq 25 \mathrm{nmol} / \mathrm{L}$, and the prevalence was 40 and $44 \%$, respectively at baseline $[11,25]$. This may indicate that the vitamin D status among women of Pakistani origin living in Denmark have improved during the last 10 years, although it is important to be aware of the present study may be affected by social selection bias as is the case with any other health- or nutrition-related intervention study.

Observational studies report increased bone resorption with vitamin D deficiency [35, 36]. Despite observations of increased bone turnover, RCT's assessing the effect of vitamin D supplementation on markers of bone turnover have shown inconsistent results [25, 26, 37-39].

Our study differs from these previous RCT's by including both women of Pakistani origin and Danish origin and we used four different vitamin D fortified foods instead of a vitamin $\mathrm{D}$ supplements. The relatively high baseline serum $25(\mathrm{OH}) \mathrm{D}$ concentration seen among the women of Danish and Pakistani origin of 49.6 (18) and 46.9 (22) nmol/L, respectively, may be a reason for not finding an effect of vitamin D supplementation on 
Table 4 Muscle strength and body composition at baseline, endpoint and the change following intervention'

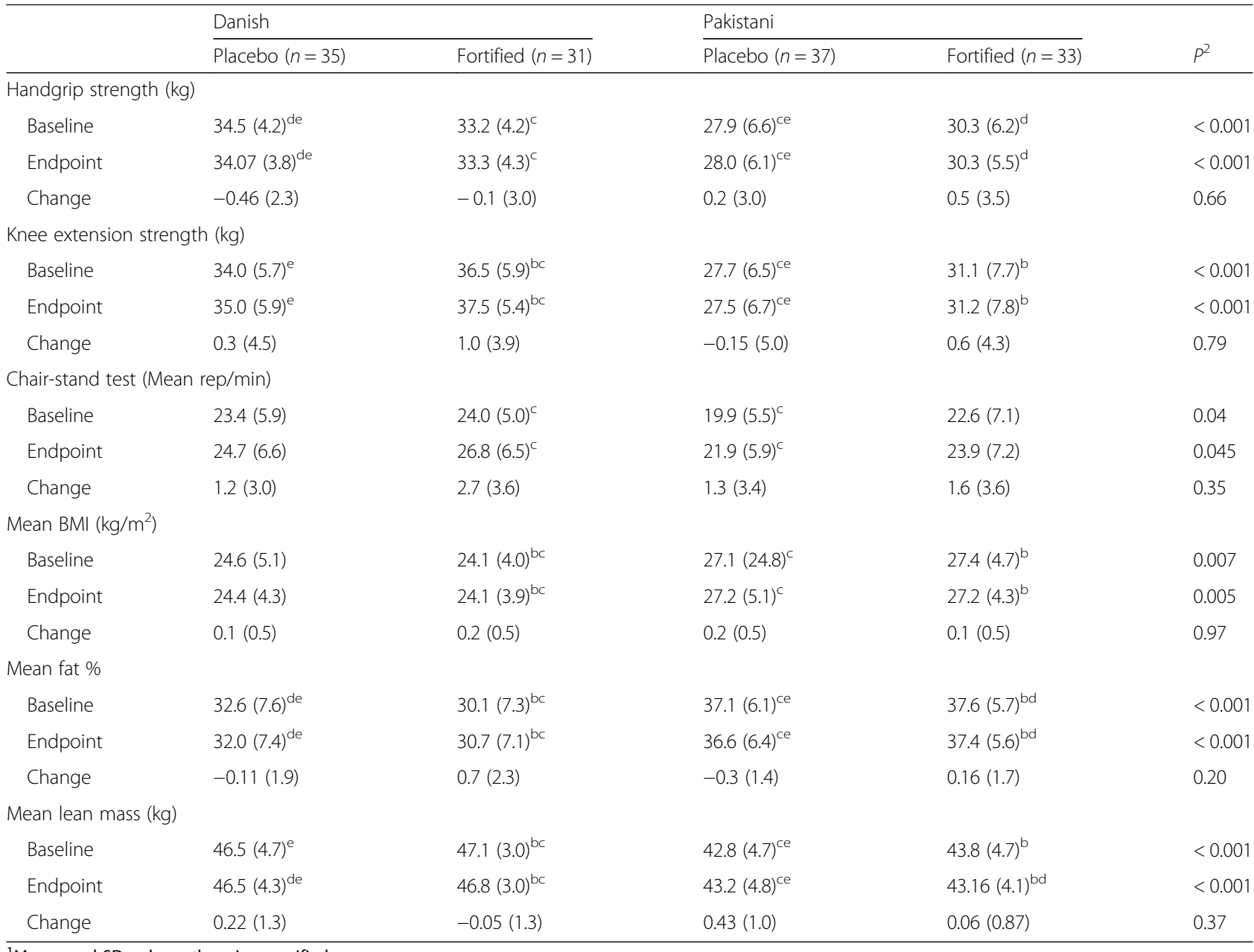

${ }^{1}$ Means and SD unless otherwise specified.

${ }^{2} P$ values for comparisons over the four study group were determined with the use of a one-way ANOVA followed by Tukey's test. Significant comparisons a: DK Placebo vs DK Fortified, b: PA Fortified vs DK Fortified, c: PA Placebo vs DK Fortified, d: PA Fortified vs DK Placebo, e: PA Placebo vs DK Placebo, f: PA Placebo vs PA Fortified.

markers of bone turnover. When vitamin D status is above the suggested cut off optimal concentration $(>50$ $\mathrm{nmol} / \mathrm{L}), \mathrm{PTH}$ concentration will be within the normal range and calcium will not be released from the bone matrix to support the calcium balance [36].

Observational data have shown correlations between vitamin D status and muscle strength [40], however, when studied in RCT's the effects of vitamin D appear inconclusive [41]. The majority of the published studies have been performed in older adults (> 50 years). Two larger systematic review and meta-analyses including 17 and 30 RCT's, respectively, found that the effect of vitamin D supplementation may only be present among vitamin D deficient people (Vitamin D concentrations < $25-30 \mathrm{nmol} / \mathrm{L})[18,19]$. A smaller systematic review and meta-analysis assessing healthy young adults $(18-40 \mathrm{y})$ included six RCT's and one controlled study assessing upper and lower limb strength and vitamin D. The authors conclude that vitamin D supplementation had a significant positive effect on muscle strength, and also that the lack of studies in the young adult population calls for further studies [42].

A Danish study assessed the effects of high dose $(2500 \mu \mathrm{g} /$ week for 1 month followed by $2500 \mu \mathrm{g} /$ month for 5 months) vitamin D supplementation in women of Arabic origin $(n=55)$ with a Danish control group $(n=22)$. The women of Arabic origin had a baseline serum 25(OH)D concentration of $6.7(0.6)$ $\mathrm{nmol} / \mathrm{L}$ compared to the women of Danish origin having a serum $25(\mathrm{OH}) \mathrm{D}$ concentration of 47.1 (4.6) $\mathrm{nmol} / \mathrm{L}$. A very low baseline knee extension strength (maximum voluntary) was found among the women of Arabic origin of $26.4 \mathrm{~kg}$, which was $34 \%$ lower than the $32.7 \mathrm{~kg}$ among the women of Danish origin. After high dose treatment, the ethnic difference disappeared. In addition, a significant reduction in reports 
Table 5 The effect of intervention with vitamin D fortified foods on the markers of bone turnover OC, BALP, P1NP and CTX, analysed in an ANCOVA including the baseline covariates that may influence the outcome (age, ethnicity, intervention group and BMI)

\begin{tabular}{|c|c|c|c|c|c|c|}
\hline Coefficients & Estimate & $95 \% \mathrm{Cl}$ & $P$ & Estimate & $95 \% \mathrm{Cl}$ & $P$ \\
\hline$\overline{\Delta O C}$ & \multicolumn{3}{|c|}{ Model 1 (minimal) } & \multicolumn{3}{|c|}{ Model 2 (maximal) } \\
\hline Intercept $^{1}$ & 3.14 & $(0.95 ; 5.32)$ & $0.005(* *)$ & 6.53 & $(1.69 ; 11.4)$ & $0.01\left(^{*}\right)$ \\
\hline Baseline OC & -0.20 & $(-0.27 ;-0.12)$ & $\left.<0.0001{ }^{(* *}\right)$ & -0.21 & $(-0.29 ;-0.13)$ & $<0.0001$ \\
\hline \multicolumn{7}{|l|}{ Ethnicity: } \\
\hline Danish & - & - & - & - & - & - \\
\hline Pakistani & 0.50 & $(-0.87 ; 1.83)$ & 0.50 & -0.70 & $(-0.67 ; 2.07)$ & 0.31 \\
\hline \multicolumn{7}{|c|}{ Intervention group: } \\
\hline Fortified & -0.57 & $(-1.87 ; 0.72)$ & 0.39 & -0.60 & $(-1.86 ; 0.66)$ & 0.35 \\
\hline Placebo & - & - & - & - & - & - \\
\hline BMI & & & & -0.10 & $(-0.25 ; 0.05)$ & 0.20 \\
\hline Age & & & & -0.01 & $(-0.08 ; 0.06)$ & 0.69 \\
\hline$\triangle \mathrm{BALP}$ & \multicolumn{3}{|c|}{ Model 1 (minimal) } & \multicolumn{3}{|c|}{ Model 2 (maximal) } \\
\hline Intercept $^{1}$ & 3.4 & $(1.93 ; 4.94)$ & $<0.0001\left(^{* * *}\right)$ & 0.50 & $(-2.6 ; 3.59)$ & 0.75 \\
\hline Baseline BALP & -0.32 & $(-0.40 ;-0.24)$ & $\left.<0.0001{ }^{(* * *}\right)$ & -0.25 & $(-0.33 ;-0.17)$ & $<0.0001^{(* * *)}$ \\
\hline \multicolumn{7}{|l|}{ Ethnicity: } \\
\hline Danish & - & - & - & - & - & - \\
\hline Pakistani & 0.2 & $(-0.84 ; 1.23)$ & 0.71 & 0.07 & $(-0.93 ; 1.08)$ & 0.88 \\
\hline \multicolumn{7}{|c|}{ Intervention group: } \\
\hline Fortified & -0.03 & $(-1.06 ; 1.00)$ & 0.95 & 0.19 & $(-0.76 ; 1.13)$ & 0.70 \\
\hline Placebo & - & - & - & - & - & - \\
\hline BMI & & & & 0.05 & $(-0.07 ; 0.16)$ & 0.43 \\
\hline Age & & & & 0.02 & $(-0.03 ; 0.07)$ & 0.42 \\
\hline$\triangle \mathrm{P} 1 \mathrm{NP}$ & \multicolumn{3}{|c|}{ Model 1 (minimal) } & \multicolumn{3}{|c|}{ Model 2 (maximal) } \\
\hline Intercept $^{1}$ & 6.81 & $(1.78 ; 11.84)$ & $0.005(* *)$ & 13.4 & $(1.10 ; 25.8)$ & $0.03(*)$ \\
\hline Baseline P1NP & -0.17 & $(-0.25 ;-0.09)$ & $\left.<0.0001{ }^{* * *}\right)$ & -0.19 & $(-0.28 ;-0.11)$ & $<0.0001{ }_{(* * *)}$ \\
\hline \multicolumn{7}{|l|}{ Ethnicity: } \\
\hline Danish & - & - & - & - & - & - \\
\hline Pakistani & 1.88 & $(-1.52 ; 5.28)$ & 0.28 & 1.79 & $(-1.78 ; 5.35)$ & 0.32 \\
\hline \multicolumn{7}{|c|}{ Intervention group: } \\
\hline Fortified & -1.36 & $(-4.75 ; 2.04)$ & 0.43 & -1.63 & $(-5.02 ; 1.76)$ & 0.34 \\
\hline Placebo & - & - & - & - & - & - \\
\hline BMI & & & & 0.04 & $(-0.37 ; 0.45)$ & 0.85 \\
\hline Age & & & & -0.18 & $(-0.36 ; 0.01)$ & 0.07 \\
\hline$\Delta C T X$ & \multicolumn{3}{|c|}{ Model 1 (minimal) } & \multicolumn{3}{|c|}{ Model 2 (maximal) } \\
\hline Intercept $^{1}$ & 0.06 & $(0.03 ; 0.10)$ & $\left.<0.0001{ }^{(* * *}\right)$ & $7.2^{-2}$ & $(-0.03 ; 0.17)$ & 0.15 \\
\hline Baseline CTX & -0.33 & $(-0.42 ;-0.23)$ & $<0.0001$ (**) $^{* *}$ & -0.33 & $(-0.43 ;-0.23)$ & $\left.<0.0001{ }^{* * *}\right)$ \\
\hline \multicolumn{7}{|l|}{ Ethnicity: } \\
\hline Danish & - & - & - & - & - & - \\
\hline Pakistani & -0.004 & $(-0.03 ; 0.02)$ & 0.80 & -0.003 & $(-0.03 ; 0.03)$ & 0.82 \\
\hline \multicolumn{7}{|c|}{ Intervention group: } \\
\hline Fortified & -0.01 & $(-0.04 ; 0.02)$ & 0.40 & -0.01 & $(-0.04 ; 0.01)$ & 0.37 \\
\hline Placebo & - & - & - & - & - & - \\
\hline
\end{tabular}


Table 5 The effect of intervention with vitamin D fortified foods on the markers of bone turnover OC, BALP, P1NP and CTX, analysed in an ANCOVA including the baseline covariates that may influence the outcome (age, ethnicity, intervention group and $\mathrm{BMI}$ (Continued)

\begin{tabular}{|c|c|c|c|c|c|c|}
\hline Coefficients & Estimate & $95 \% \mathrm{Cl}$ & $P$ & Estimate & $95 \% \mathrm{Cl}$ & $P$ \\
\hline $\mathrm{BMI}$ & & & & $-2.1^{-4}$ & $(-0.004 ; 0.003)$ & 0.91 \\
\hline Age & & & & $-2.8^{-6}$ & $(-0.002 ; 0.002)$ & 1.00 \\
\hline
\end{tabular}

${ }^{1}$ The reference group is included in the intercept: Danish ethnicity and placebo study group

Table 6 The change in muscle strength measured as handgrip strength and knee extension strength and a 30 s chair-standing test, analysed in an ANCOVA including the baseline covariates that may influence the outcome (age, ethnicity, intervention group and BMI)

\begin{tabular}{|c|c|c|c|c|c|c|}
\hline Coefficients & Estimate & $95 \% \mathrm{Cl}$ & $P$ & Estimate & $95 \% \mathrm{Cl}$ & $P$ \\
\hline$\Delta$ Handgrip strength & \multicolumn{3}{|c|}{ Model 1 (minimal) } & \multicolumn{3}{|c|}{ Model 2 (maximal) } \\
\hline Intercept $^{1}$ & 6.80 & $(3.56 ; 10.0)$ & $<0.0001{ }^{(* * *)}$ & 6.56 & $(2.32 ; 10.8)$ & $<0.003\left(^{(*)}\right.$ \\
\hline Baseline handgrip strength & -0.21 & $(-0.31 ;-0.12)$ & $\left.<0.0001{ }^{(* * *}\right)$ & -0.22 & $(-0.31 ;-0.12)$ & $\left.<0.00011^{(* *}\right)$ \\
\hline \multicolumn{7}{|l|}{ Ethnicity: } \\
\hline Danish & - & - & - & - & - & - \\
\hline Pakistani & -0.53 & $(-1.63 ; 0.58)$ & 0.35 & -0.63 & $(-1.82 ; 0.56)$ & 0.30 \\
\hline \multicolumn{7}{|l|}{ Intervention group: } \\
\hline Fortified & 0.38 & $(-0.62 ; 1.37)$ & 0.46 & 0.48 & $(-0.54 ; 1.50)$ & 0.35 \\
\hline Placebo & - & - & - & - & - & - \\
\hline BMI & & & & 0.01 & $(-0.11 ; 0.13)$ & 0.88 \\
\hline Age & & & & -0.003 & $(-0.05 ; 0.06)$ & 0.99 \\
\hline$\Delta$ Knee extension strength & \multicolumn{3}{|c|}{ Model 1 (minimal) } & \multicolumn{3}{|c|}{ Model 2 (maximal) } \\
\hline Intercept $^{1}$ & 8.66 & $(4.16 ; 13.16)$ & $<0.0001{ }^{(* *)}$ & 9.93 & $(3.82 ; 16.21)$ & $\left.<0.00011^{(* *}\right)$ \\
\hline Baseline knee extension strength & -0.24 & $(-0.37 ;-0.12)$ & $<0.0001\left(^{* * *}\right)$ & -0.25 & $(-0.38 ;-0.12)$ & $\left.<0.00011^{(* *}\right)$ \\
\hline \multicolumn{7}{|l|}{ Ethnicity: } \\
\hline Danish & - & - & - & - & - & - \\
\hline Pakistani & -1.96 & $(-3.69 ;-0.23)$ & $0.03(*)$ & -1.95 & $(-4.24 ; 0.54)$ & $0.03(*)$ \\
\hline \multicolumn{7}{|l|}{ Intervention group: } \\
\hline Fortified & 1.23 & $(-0.34 ; 2.81)$ & 0.12 & 1.21 & $(-0.94 ; 3.52)$ & 0.13 \\
\hline Placebo & - & - & - & - & - & - \\
\hline BMI & & & & -0.02 & $(-0.20 ; 0.18)$ & 0.87 \\
\hline Age & & & & -0.03 & $(-0.11 ; 0.06)$ & 0.46 \\
\hline$\Delta$ Chair-standing test & \multicolumn{3}{|c|}{ Model 1 (minimal) } & \multicolumn{3}{|c|}{ Model 2 (maximal) } \\
\hline Intercept $^{1}$ & 2.54 & $(-0.22 ; 5.31)$ & 0.07 & 5.90 & $(0.78 ; 11.0)$ & $0.02(*)$ \\
\hline Baseline chair-standing & -0.05 & $(-0.15 ; 0.06)$ & 0.41 & -0.06 & $(-0.17 ; 0.06)$ & 0.30 \\
\hline \multicolumn{7}{|l|}{ Ethnicity: } \\
\hline Danish & - & - & - & - & - & - \\
\hline Pakistani & -0.56 & $(-1.86 ; 0.74)$ & 0.39 & -0.01 & $(-1.45 ; 1.24)$ & 0.88 \\
\hline \multicolumn{7}{|l|}{ Intervention group: } \\
\hline Fortified & 0.94 & $(-0.34 ; 2.22)$ & 0.15 & 0.93 & $(-0.34 ; 2.20)$ & 0.15 \\
\hline Placebo & - & - & - & - & - & - \\
\hline BMl & & & & -0.16 & $(-0.31 ;-0.004)$ & $0.04(*)$ \\
\hline Age & & & & 0.02 & $(-0.05 ; 0.09)$ & 0.56 \\
\hline
\end{tabular}

${ }^{1}$ The reference group is included in the intercept: Danish ethnicity and placebo study group 
of muscle and bone pain among the women of Arabic origin [43].

In the present study the serum $25(\mathrm{OH}) \mathrm{D}$ concentration in the placebo groups decreased by $2.8(9) \mathrm{nmol} / \mathrm{L}$ in the Danish placebo group and by 11.2 (12) $\mathrm{nmol} / \mathrm{L}$ in the Pakistani placebo group, however we did not see a significant decrease in muscle strength and bone formation markers or increase of the bone resorption marker (CTX) following the intervention. Based on the above, the present study suggests that a vitamin $\mathrm{D}$ status of $\approx$ $50 \mathrm{nmol} / \mathrm{L}$ measured at winter time (start of January) would be sufficient to maintain healthy muscle and bone during the following winter months.

\section{Strengths and limitations}

The ODIN FOOD study was carried out in winter which is a strength in relation to avoiding confounding from vitamin D originating from UVB sources as no cutaneous production of vitamin $\mathrm{D}$ occurs during the months of winter (October-April) at Danish latitudes [10, 44]. An additional strength was the real-life setting of the study and thereby the applicability of the results in a public health setting. A limitation affecting health and nutrition studies in general is the bias of social selection during recruitment, this may also be a factor in this study. The fact that the participants may be a selected group, must be taken into account when interpreting the results.

The study was designed to detect the effect of vitamin D fortification on serum 25(OH)D concentration and thus, the power calculation was made with vitamin $\mathrm{D}$ status as the response variable. This may affect the results of secondary endpoint analyses such as muscle strength and bone markers due to a too low power to detect relevant changes in the mentioned endpoints.

Several limitations are present when using markers of bone remodelling. Large pre-analytical and analytical variability are seen and markers of bone turnover are affected by modifiable factors such as circadian rhythm, season, ethnicity, fasting state, physical activity and menstrual cycle [14]. Additionally, there are no standardised assays for bone markers. Since we were not able to obtain fasting blood samples from the participants due to logistical reasons, we attempted to book the participant at the same hour of the day at the two different measurements in order to minimise the preanalytical variability.

With regard to the study duration, 12 weeks has been shown to be the minimum time used in previous studies and may in fact have been too short a period to detect any changes in muscle strength and bone markers [19, 26] especially if the participants are in a vitamin $D$ replete state of vitamin $\mathrm{D}$, little may change following an intervention with vitamin $\mathrm{D}$ [19].
At baseline, the participants would perform the muscle test for the first time, whereas at the endpoint measurement there may be some familiarity of the muscle tests. Despite performing familiarisation trials before the tests, and giving the participants up to two additional muscle tests trials if the last one were the highest we cannot rule out that this may influence the score because of inexperience and reluctance to exert full capacity of power at baseline, compared to the endpoint.

Although successfully developed for older adults [29], the $30 \mathrm{~s}$ chair-stand test has also been used on people within our target group [45]. However, this test may not be completely optimal for this target group because the participants may have memorised their own baseline test results and some may even have tried to improve their score at the endpoint test. Also, participants with good physical fitness performed the test so fast that some had problems with the balance as a result of this.

\section{Conclusion}

Consumption of vitamin D fortified foods for 12 weeks did not result in significant changes of the bone turnover markers OC, BALP, P1NP and CTX. Muscle strength measured as hand grip strength, knee extension strength and chair-standing did not change significantly following the intervention.

\section{Abbreviations}

25(OH)D: Serum 25-hydroxyvitamin D; ANCOVA: Analysis of co-variance; ANOVA: Analysis of variance; BALP: Bone specific Alkaline Phosphatase; BMD: Bone Mineral Density; CTX: C-terminal crosslinked telopeptide of type 1 collagen; DTU: Technical University of Denmark; FFQ: Food Frequency Questionnaire; IOF: International Osteoporosis Foundation; LC-MS/MS: Liquid chromatography-tandem mass spectrometry; OC: Osteocalcin; ODIN: Foodbased solutions for optimal vitamin D nutrition and health through the life cycle; P1NP: Procollagen type 1 amino-terminal propeptide;

RCT: Randomised Controlled trial; SD: Standard Deviation; UCC: University College Cork; VDR: Vitamin D receptor; VDSP: Vitamin D Standardization Program

\section{Acknowledgements}

We thank Majken Ege, Karin Hess Ygil, Dorte L Korsbech, Erika Baig for assisting with the measurements, dietary intake calculations and FFQ work, Bashy Quraishy, Raza Mustafa, Saima Raza, Shahnaz Qureshi and Shais Anais for introducing us to the Pakistani societies in Copenhagen, Denmark. We thank our industrial partners FrieslandCampina, Hedegaard, Lantmännen Cerealia and DSM nutritional products for delivering the foods used in the trial.

\section{Authors' contributions}

RA and IT designed the study; MK, REKL, TLLT, IMG and RA collected the data, MK, REKL and TLLT designed the muscle strength tests and managed the muscle strength data; IMG undertook the statistical analyses and wrote this paper. All contributed to the manuscript. All authors read and approved the final manuscript.

\section{Funding}

This research was undertaken by the National Food Institute, Technical University of Denmark (DTU) and the study was a part of the European collaborative project "Food-based solutions for eradication of vitamin D deficiency and health promotion throughout the life cycle - ODIN", which was funded by the European Commission (FP7/2007-2013) under grant agreement no. 613977 (ODIN) and the National Food Institute, Technical 
University of Denmark and department of Nursing and Nutrition, Faculty of Health, University College Copenhagen. The cheese and yoghurt products were produced and provided free of cost by FrieslandCampina. The eggs were produced and provided free of cost by Hedegaard Agro, including chicken feed produced by Dava Foods, the crisp-bread was produced by Smørum konditori (confectionary) with ingredients supplied free of cost by Lantmännen cerealia and vitamin $D_{3}$ supplied by DSM Nutritional Products.

\section{Availability of data and materials}

The data can be made available on reasonable request to the corresponding author.

\section{Ethics approval and consent to participate}

Written informed consent was obtained from all participants on enrolment. The study protocol was approved by the local ethical committee (protocol no. $\mathrm{H}-15008276)$ and registered at ClinicalTrials.gov with identifier: NCT02631629. The study was carried out in accordance with the Declaration of Helsinki.

\section{Consent for publication}

All authors have given consent for the paper to be published by the corresponding author.

\section{Competing interests}

None of the authors had conflicts of interest. The industry partners had no influence on the design of the study, or the interpretation of the results.

\section{Author details}

'National Food Institute, Technical University of Denmark, Lyngby, Denmark. ${ }^{2}$ Division Diet, Disease Prevention and Toxicology, National Food Institute, Technical University of Denmark, Lyngby, Denmark. ${ }^{3}$ Vitality - Centre for good older lives, Department of Nutrition, Exercise and Sports, University of Copenhagen, Frederiksberg C, Denmark. ${ }^{4}$ Section for Statistics and Pharmacoepidemiology, Danish Cancer Society, Copenhagen, Denmark. ${ }^{5}$ Institute of Applied Mathematics and Computer Science, Technical University of Denmark, Lyngby, Denmark. ${ }^{6}$ Department of Nursing and Nutrition, Faculty of Health, University College Copenhagen, Copenhagen, Denmark.

Received: 9 April 2019 Accepted: 12 November 2019

Published online: 02 December 2019

\section{References}

1. Holick MF. Resurrection of vitamin D deficiency and rickets. J Clin Invest. 2006;116:2062-72.

2. DeLuca HF. Overview of general physiologic features and functions of vitamin D. The American journal of clinical nutrition. 2004;80 6 Suppl.

3. Ross AC, Taylor CL, Yaktine AL, Del Valle HB. Calcium and Vitamin D. Washington D.C.: Institute of Medicine, the National Academic Press; 2011.

4. EFSA Panel on Dietetic Products Nutrition and Allergies (NDA). Scientific Opinion on Dietary Reference Values for vitamin D. EFSA J. 2016:1-179.

5. Pfeifer M, Begerow B, Minne HW. Vitamin D and muscle function. Osteoporos Int. 2002;13:187-94.

6. Kalliokoski $P$, Bergqvist $Y$, Löfvander M. Physical performance and 25 hydroxyvitamin D: a cross-sectional study of pregnant Swedish and Somali immigrant women and new mothers. BMC Pregnancy Childbirth. 2013;13:1-9

7. Visser M, Deeg DJH, Lips P. Low vitamin D and high parathyroid hormone levels as determinants of loss of muscle strength and muscle mass (sarcopenia): the longitudinal aging study Amsterdam. J Clin Endocrinol Metab. 2003;88:5766-72. https://doi.org/10.1210/jc.2003-030604.

8. Holick M, Chen T. Vitamin D deficiency: a worldwide problem with health consequences. Am J Clin Nutr. 2008;87:1080-6.

9. Brot C, Vestergaard P, Kolthoff N, Gram J, Hermann AP, Sørensen OH. Vitamin D status and its adequacy in healthy Danish perimenopausal women: relationships to dietary intake, sun exposure and serum parathyroid hormone. Br J Nutr. 2001:86:97-103.

10. Thuesen $B$, Husemoen L, Fenger M, Jakobsen J, Schwarz P, Toft U, et al. Determinants of vitamin D status in a general population of Danish adults. Bone. 2012;50:605-10
11. Andersen R, Mølgaard C, Skovgaard LT, Brot C, Cashman KD, Jakobsen J, et al. Pakistani immigrant children and adults in Denmark have severely low vitamin D status. Eur J Clin Nutr. 2008;62:625-34.

12. Andersson $\AA$, Björk A, Kristiansson P, Johansson G. Vitamin D intake and status in immigrant and native Swedish women: a study at a primary health care Centre located at 60 oN in Sweden. Food Nutr Res. 2013;1:1-8.

13. Meyer HE, Falch JA, Søgaard AJ, Haug E. Vitamin D deficiency and secondary hyperparathyroidism and the association with bone mineral density in persons with Pakistani and Norwegian background living in Oslo, Norway. The Oslo Health Study Bone. 2004;35:412-7.

14. Shetty S, Kapoor N, Bondu J, Thomas N, Paul T. Bone turnover markers: emerging tool in the management of osteoporosis. Indian J Endocrinol Metab. 2016:20:846. https://doi.org/10.4103/2230-8210.192914.

15. Wheater G, Elshahaly M, Tuck SP, Datta HK, van Laar JM. The clinical utility of bone marker measurements in osteoporosis. J Transl Med. 2013:11:1. https://doi.org/10.1186/1479-5876-11-201

16. Hamilton B. Vitamin D and Human Skeletal Muscle. Scand J Med Sci Sport. 2010;20:182-90

17. Girgis CM, Clifton-Bligh RJ, Hamrick MW, Holick MF, Gunton JE. The roles of vitamin D in skeletal muscle: form, function, and metabolism. Endocr Rev. 2013;34:33-83.

18. Beaudart C, Buckinx F, Rabenda V, Gillain S, Cavalier E, Slomian J, et al. The effects of vitamin d on skeletal muscle strength, muscle mass, and muscle power: a systematic review and meta-analysis of randomized controlled trials. J Clin Endocrinol Metab. 2014;99:4336-45.

19. Stockton KA, Mengersen K, Paratz JD, Kandiah D, Bennell KL. Effect of vitamin D supplementation on muscle strength: a systematic review and meta-analysis. Osteoporos Int. 2011;22:859-71. https://doi.org/10.1007/ s00198-010-1407-y.

20. Murad MH, Elamin KB, Abu Elnour NO, Elamin MB, Alkatib A. A, Fatourechi $M M$, et al. clinical review: the effect of vitamin D on falls: a systematic review and meta-analysis. J Clin Endocrinol Metab. 2011:96(10):2997-3006.

21. Dewansingh $P$, Melse-Boonstra $A$, Krijnen WP, van der Schans $C P$, JagerWittenaar $\mathrm{H}$, van den Heuvel EGHM. Supplemental protein from dairy products increases body weight and vitamin D improves physical performance in older adults: a systematic review and meta-analysis. Nutr Res. 2018;49:1-22

22. Rejnmark $L$. Effects of vitamin $D$ on muscle function and performance: review of evidence from randomized controlled trials. Ther Adv Chronic Dis. 2011:2:25-37.

23. Grønborg, IM; Tetens, I; Christensen, T; Andersen, EW; Jakobsen, J; Kiely, M; Cashman, KD; Andersen R. Vitamin D fortified foods improve wintertime vitamin $D$ status in women of Danish and Pakistani origin living in Denmark: A randomized controlled trial. Eur J Nutr. 2019;:Online 09 March. doi:https://doi.org/10.1007/s00394-019-01941-6.

24. Pedersen AN, Christensen T, Matthiessen J, Knudsen VK, RosenlundSørensen M, Biltoft-Jensen A, et al. Danskernes kostvaner 2011-2013 [Danish Dietary survey]. Søborg; 2015

25. Andersen R, Mølgaard C, Skovgaard LT, Brot C, Cashman KD, Jakobsen J, et al. Effect of vitamin D supplementation on bone and vitamin D status among Pakistani immigrants in Denmark: a randomised double-blinded placebo-controlled intervention study. Br J Nutr. 2008;100:197-207. https:// doi.org/10.1017/S000711450789430X

26. Madar AA, Knutsen KV, Stene LC, Brekke M, Lagerløv P, Meyer HE, et al. Effect of vitamin D3-supplementation on bone markers (serum P1NP and CTX): a randomized, double blinded, placebo controlled trial among healthy immigrants living in Norway. Bone Reports. 2015;2:82-8. https://doi.org/10. 1016/j.bonr.2015.05.004

27. Virgil Mathiowetz MS, Kashman N, Volland G, Karen BS, Weber BS, Mary Dowe SR. Grip and pinch Strenght: Normative data for Adults. Arch Phys Med Rehabil. 1985;66(2):69-74.

28. Bohannon RW, Kindig J, Sabo G, Duni AE, Cram P. Isometric knee extension force measured using a handheld dynamometer with and without beltstabilization. Physiother Theory Pract. 2012;28(7):562-8.

29. Jones CJ, Rikli RE, Beam WC. A 30-s chair-stand test as a measure of lower body strength in community-residing older adults. Res Q Exerc Sport. 1999; 70(2):113-9.

30. Cashman KD, Kiely M, Kinsella M, Durazo-Arvizu RA, Tian L, Zhang Y, et al. Evaluation of vitamin D standardization program protocols for standardizing serum 25-hydroxyvitamin D data: a case study of the program's potential for national nutrition and health surveys. Am J Clin Nutr. 2013;97:1235-42. 
31. Patel SS, Molnar MZ, Tayek JA, Ix JH, Noori N, Benner D, et al. Serum creatinine as a marker of muscle mass in chronic kidney disease: results of a cross-sectional study and review of literature. J Cachexia Sarcopenia Muscle. 2013:4:19-29.

32. Team RC. R: A language and environment for statistical computing. $R$ Foundation for Statistical Computing. Vienna, Austria; 2017. https://www.rproject.org/

33. Madsen $\mathrm{KH}$, Rasmussen LB, Andersen R, Mølgaard C, Jakobsen J, Bjerrum PJ, et al. Randomized controlled trial of the effects of vitamin $D$ - fortified milk and bread on serum 25 -hydroxyvitamin $D$ concentrations in families in Denmark during winter : the VitmaD study 1-3. Am J Clin Nutr. 2013:98 May:374-382.

34. Hansen L, Tøønneland A, Køster B, Brot C, Andersen R, Cohen AS, et al. Vitamin $D$ status and seasonal variation among danish children and adults: a descriptive study. Nutrients. 2018:10.

35. Sahota O, Masud T, San P, Hosking DJ. Vitamin D insufficiency increases bone turnover markers and enhances bone loss at the hip in patients with established vertebral osteoporosis. Clin Endocrinol. 1999;51(2):217-21.

36. Need AG. Bone resorption markers in vitamin D insufficiency. Clin Chim Acta. 2006;368:48-52.

37. Lowe NM, Mitra SR, Foster PC, Bhojani I, McCann JF. Vitamin D status and markers of bone turnover in Caucasian and south Asian postmenopausal women living in the UK. Br J Nutr. 2010;103:1706-10.

38. Schwetz V, Trummer C, Pandis M, Grübler MR, Verheyen N, Gaksch M, et al. Effects of vitamin $D$ supplementation on bone turnover markers: a randomized controlled trial. Nutrients. 2017:9:1-11.

39. Nahas-Neto J, Cangussu LM, Orsatti CL, Bueloni-Dias FN, Poloni PF, Schmitt $E B$, et al. Effect of isolated vitamin $D$ supplementation on bone turnover markers in younger postmenopausal women: a randomized, double-blind, placebo-controlled trial. Osteoporos Int. 2018;29:1125-33.

40. Bischoff-Ferrari HA, Dietrich T, Orav EJ, Hu FB, Zhang Y, Karlson EW, et al. Higher 25-hydroxyvitamin D concentrations are associated with better lower-extremity function in both active and inactive persons aged $>$ or $=60$ y. Am J Clin Nutr. 2004;80:752-8 http://www.ncbi.nlm.nih.gov/ pubmed/15321818.

41. Rejnmark L, Bislev LS, Cashman KD, Eiríksdottir G, Gaksch M, Grübler M, et al. Non-skeletal health effects of vitamin $D$ supplementation: a systematic review on findings from meta-analyses summarizing trial data. PLoS One. 2017:12:1-39.

42. Tomlinson PB, Joseph C, Angioi M. Effects of vitamin D supplementation on upper and lower body muscle strength levels in healthy individuals. A systematic review with meta-analysis. J Sci Med Sport. 2015;18(5):575-80.

43. Glerup H, Mikkelsen K, Poulsen L, Hass E, Overbeck S, Andersen H, et al. Hypovitaminosis D myopathy without biochemical signs of osteomalacic bone involvement. Calcif Tissue Int. 2000;66:419-24 http://www.ncbi.nlm. nih.gov/pubmed/10821877.

44. Kimlin MG. Geographic location and vitamin D synthesis. Mol Asp Med. 2008:29:453-61. https://doi.org/10.1016/..mam.2008.08.005.

45. Hansen AW, Beyer N, Flensborg-Madsen T, Grønbæk M, Helge JW. Muscle strength and physical activity are associated with self-rated health in an adult Danish population. Prev Med (Baltim). 2013;57(6):792-8.

\section{Publisher's Note}

Springer Nature remains neutral with regard to jurisdictional claims in published maps and institutional affiliations.

Ready to submit your research? Choose BMC and benefit from:

- fast, convenient online submission

- thorough peer review by experienced researchers in your field

- rapid publication on acceptance

- support for research data, including large and complex data types

- gold Open Access which fosters wider collaboration and increased citations

- maximum visibility for your research: over $100 \mathrm{M}$ website views per year

At $\mathrm{BMC}$, research is always in progress.

Learn more biomedcentral.com/submissions 